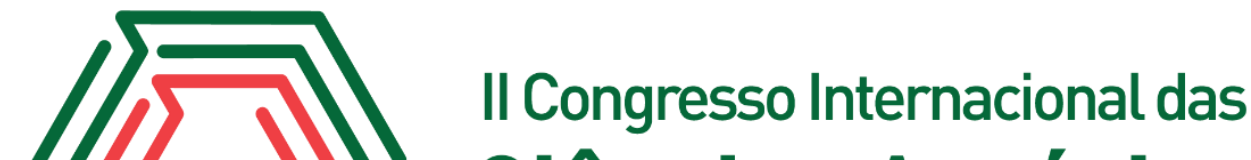 Ciências Agrárias COINTER - PDVAgro 2017
}

\section{PRODUÇÃO AGROECOLÓGICA INTEGRADA E SUSTENTÁVEL (PAIS) NA COMUNIDADE VILA DO OITEIRO EM VITÓRIA DE SANTO ANTÃO - PE}

\author{
Apresentação: Relato de Experiência \\ Maria José Querino da Silva ${ }^{1}$; Joaquim Francisco da Silva ${ }^{2}$; Maciel Alves Tavares ${ }^{3}$; Marta Xavier \\ de Carvalho Correia ${ }^{4}$; Mércia Cardoso da Costa Guimarães ${ }^{5}$
}

\section{Introdução}

A tecnologia social Produção Agroecológica Integrada e Sustentável (PAIS) vem sendo multiplicada no Brasil desde o ano 2005, principalmente em pequenas propriedades rurais com objetivo de buscar a segurança e a soberania alimentar e a geração de renda (NDIAYE, 2016).A questão de segurança alimentar não é vista somente do ponto de vista da quantidade de alimentos, mas também da qualidade e da diversidade.

A agricultura familiar deve ser valorizada como um segmento gerador de emprego e renda, de modo a estabelecer um padrão de desenvolvimento rural sustentável, através da produção de alimentos saudáveis que venham garantir uma melhor qualidade de vida para as famílias.

Atingir padrões de desenvolvimento da agricultura familiar, tendo em vista à realidade da maioria das unidades agrícolas brasileiras, onde há baixo custo de oportunidade do trabalho rural pode ser alcançado a partir de projetos modestos que elevem o nível de vida de populações (ABRAMOVAY, 1998). Para implantação do projeto PAIS realizamos diagnósticos na comunidade Vila do Oiteiro para sabermos quais as condições da segurança alimentar e nutricional das famílias. Após o diagnóstico, iremos capacitar os agricultores sobre o projeto PAIS e a implantação deste na comunidade.

\section{Relato de Experiência}

Realizamos visita à comunidade Vila do Oiteiro no município de Vitória de Santo Antão,

\footnotetext{
${ }^{1}$ Subsequente em Zootecnia, IFPE Campus Vitória,mrenata.cgpe@ gmail

${ }^{2}$ Subsequente em Zootecnia, IFPE Campus Vitória, joaquimf1523@hotmail.com

${ }^{3}$ Agronomia, IFPE Campus Vitória, macieltavares15@gmail.com

${ }^{4}$ Doutorado em Produção Animal, IFPE Campus Vitória, marta.xavier@vitoria.ifpe.edu.br

${ }^{5}$ Doutorado em Engenharia Agrícola, IFPE Campus Vitória, mercia.guimaraes@ vitoria.ifpe.edu.br
} 
objetivando a apresentação do projeto PAIS (Imagem 1) e sua posterior implantação nesta comunidade. Participaram alunos e professores do Instituto Federal de Pernambuco (IFPE) Campus Vitória, a líder comunitária, bem como vários componentes dessa comunidade.

Houve uma apresentação geral das propostas do IFPE e dos projetos bem como Aplicamos questionários para realizar o diagnóstico alimentar das famílias da comunidade (Imagem 2). Foi observado que agricultores apresentaram interesse pelos projetos, sendo proposta uma visita ao IFPE local.

Todavia está visita permitiu a troca de conhecimentos, mostrando como é interessante e importante esse contato direto com as famílias para o desenvolvimento de cada comunidade, pois só é possível conhecer a realidade quando se está presente nos fatos. Foram atividades bastante proveitosas, que levaram as famílias presentes refletir, e olhar para um futuro mais proveitoso.

Imagem 1: Apresentação. Fonte: Própria

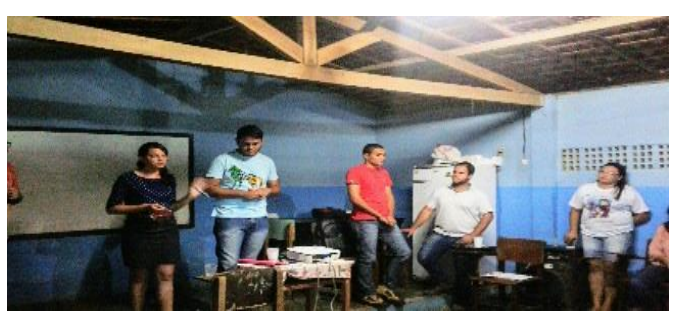

Imagem 2: Aplicação de Questionário. Fonte: Própria

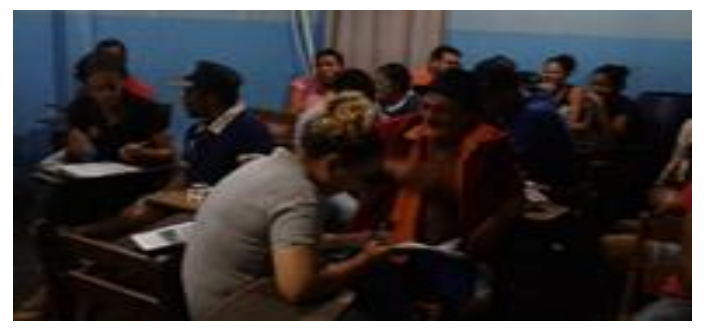

\section{Considerações}

Com a realização da visita a comunidade vila do Oiteiro foi possível divulgar o nosso projeto (PAIS), bem como os outros projetos, possibilitando aos agricultores compreenderem a importância da parceria entre a sua comunidade e o Instituto e os futuros benefícios mútuos que essa parceria poderá trazer, do ponto de vista alimentar e de conhecimentos, além de estimular o consumo de alimentos mais saudáveis.

\section{Referências}

NDIAYE.A.Análise do desenvolvimento do Programa PAIS. In. PROGRAMA DE PÓS GRADUAÇÃO EM AGRICULTURA ORGÂNICA, UFRRJ, 2016, Seropédica. Disponível em: http://cursos.ufrrj.br/posgraduacao/ppgao/files/2016/11/Aly-disserta\%C3\%A7\%C3\%A3o.pdf. Acesso em: 23 de setembro de 2017.

ABRAMOVAY, R. Agricultura familiar e desenvolvimento territorial. In. Reforma Agrária Revista da Associação Brasileira de Reforma Agrária, v. 28, n. 1,2 3.1998.Disponível em:http://http://wp.ufpel.edu.br/ppgdtsa/files/2014/10/Texto-Abramovay-R.-Agricultura-familiar-edesenvolvimento-territorial.pdf/>Acesso em:23 de setembro de 2017. 